\title{
Surface Morphology, Structural and Optical Properties of MgO Films Obtained by Spray Pyrolysis Technique
}

\author{
O.V. Diachenko ${ }^{a, b, *}$, A.S. OpanasuyK ${ }^{a}$, D.I. Kurbatov ${ }^{a}$, N.M. Opanasurk ${ }^{a}$, \\ O.K. KONONOV ${ }^{a}$, D. NAM ${ }^{b}$ AND H. CHEONG ${ }^{b}$ \\ ${ }^{a}$ Sumy State University, 2, Rymskogo-Korsakova Str., 40007 Sumy, Ukraine \\ ${ }^{b}$ Department of Physics, Sogang University, Seoul 121-742, South Korea
}

(Received November 2, 2015; in final form July 15, 2016)

\begin{abstract}
X-ray diffraction, atomic force microscopy, field emission scanning electron microscopy, UV-visible photometry, and photoluminescence measurements were used to investigate the surface morphology and structural and optical properties of $\mathrm{MgO}$ films. Magnesium oxide films deposited by the spray pyrolysis technique were studied. The substrate temperature was varied from $T_{\mathrm{s}}=643 \mathrm{~K}$ to $693 \mathrm{~K}$. Magnesium chloride hexahydrate $\left(\mathrm{MgCl}_{2} \cdot 6 \mathrm{H}_{2} \mathrm{O}\right)$, dissolved in deionized water, was used as the precursor solution. It was established that the single phase films crystallize into a cubic structure with very fine crystallite size (about $2 \mathrm{~nm}$ ). The optical band gaps of the samples were varied from $3.64 \mathrm{eV}$ to $3.70 \mathrm{eV}$. Also, the films have a high level of transmittance of $90 \%$. Photoluminescence spectra show the emission peaks at approximately $412 \mathrm{~nm}(3.00 \mathrm{eV})$ and $524 \mathrm{~nm}(2.38 \mathrm{eV})$. The peak with the energy of $3.00 \mathrm{eV}$ is ascribed to holes trapped in magnesium ion vacancies acting as acceptors $\left(\mathrm{F}^{+}\right.$center). The broad emission peak at $524 \mathrm{~nm}$ is related to the presence of defects $\left(\mathrm{F}^{-}\right.$centers) associated with oxygen ion vacancies.
\end{abstract}

DOI: 10.12693/APhysPolA.130.805

PACS/topics: 81.05.Dz, 81.15.Rs

\section{Introduction}

Recently, wide band gap metallic oxides materials $\left(\mathrm{SnO}_{2}, \mathrm{In}_{2} \mathrm{O}_{3}, \mathrm{ZnO}, \mathrm{CuO}_{2}\right.$, etc. $)$ are increasingly used in so-called transparent electronics [1]. $\mathrm{MgO}$ is a promising material for application in photovoltaics and opto- and microelectronics. It is attracting much interest owing to its unique properties such as a high dielectric constant $(\approx 9.8)$, a large band gap of $7.3-7.8 \mathrm{eV}$, and a high breakdown field of $12 \mathrm{MV} / \mathrm{cm}$ [2]. Other important properties of $\mathrm{MgO}$ include chemical inertness, high electrical insulation, optical transparency, high-temperature stability, and high thermal conductivity $[2,3]$. Such properties allow using this compound as a dielectric material to replace silicon dioxide in some applications [2]. $\mathrm{MgO}$ can also be used as a protective layer of plasma display panels to extend the service life of such panels through high durability and improved discharge characteristics [4-6]. Magnetic tunnel junctions (MTJ), where $\mathrm{MgO}$ is used as a barrier layer, are of great importance not only for the creation of microelectronic and spintronic devices but also to clarify the mechanisms of spin-dependent tunneling of electrons [7]. $\mathrm{MgO}$ as an insulating layer has played a significant role in the development of magnetic data storage devices such as nonvolatile magnetic random access memories (MRAM) [8,9]. The window layer of $\mathrm{Zn}_{0.7} \mathrm{Mg}_{0.3} \mathrm{O}$ solid solution is also considered as the optimal material for SnS-based solar cells [1].

$\mathrm{MgO}$ thin films can be obtained using the following methods: metalorganic molecular beam epitaxy [10], metalorganic chemical vapor deposition [11], pulsed laser

\footnotetext{
*corresponding author; e-mail: alexey.dyachenko@ukr.net
}

deposition [12], reactive sputtering [5], chemical vapor deposition [13], sol-gel synthesis [14], spray pyrolysis [15], etc. Because of its simplicity, low cost, high-speed deposition and the possibility of obtaining films on large area substrates using various precursors, the spray pyrolysis is an effective non-vacuum method for obtaining high-quality thin films of oxides. This method allows preparing both thin and thick films. Moreover, the produced films are homogeneous and stable with time and temperature [8].

Studies of different structural and physical properties of magnesium oxide films have been reported previously $[2,3,5,11,13,14,16-19]$. But only a few studies have dealt with films obtained by the spray pyrolysis method $[8,17,20-22]$. Moreover, only one research group has reported results of an investigation of thin films obtained at substrate temperature $503 \mathrm{~K}$ from a solution based on magnesium chloride [22]. In this work, we present a comprehensive study of the effect of deposition temperature on the surface morphology and structural and optical properties of the films synthesized from a solution of magnesium chloride in a wider temperature range.

\section{Experimental details}

Magnesium oxide thin films were obtained by spray pyrolysis using the laboratory system described in [15]. For sample preparation, glass substrates of $1 \mathrm{~mm}$ in thickness were ultrasonically cleaned for $6 \mathrm{~min}$ and then washed with deionized water and ethanol. As the precursor, 0.2 molar solution of magnesium chloride $\mathrm{MgCl}_{2} \cdot 6 \mathrm{H}_{2} \mathrm{O}$ (Kvalitet Chemical NPP, purity 99.98\%) obtained by dissolution in deionized water under constant stirring, was used. The precursor solution was sprayed using a jet 
nozzle onto a heated substrate using air as the carrier gas. The diameter of the nozzle was $0.2 \mathrm{~mm}$. The distance between the nozzle and the heated substrate surface was $15 \mathrm{~cm}$. The spraying rate was $2 \mathrm{~cm}^{3} / \mathrm{min}$, and the volume of sprayed solution $2 \mathrm{~cm}^{3}$ per sample. The substrate temperature was varied from $T_{\mathrm{s}}=643 \mathrm{~K}$ to $693 \mathrm{~K}$ with a step of $10 \mathrm{~K}$. The substrate temperature during the deposition was monitored using a chromel-alumel thermocouple located on the backside of the glass substrate.

The thickness of the samples was determined using a Dektak XT profiler. The measurements were carried out relative to the area of the substrate without a magnesium oxide layer. The measurement parameters were: scan length of $3000 \mu \mathrm{m}$, resolution of $0.001 \mu \mathrm{m}$, stylus force of $3 \mathrm{mg}$, and stylus scan range of $65.5 \mu \mathrm{m}$.

A field emission scanning electron microscope (FESEM; JEOL JSM-7600F) was used to investigate the morphology of the obtained layers. The surface morphology was probed using an atomic force microscope (AFM; NT-MDT NTEGRA Spectra). The scan area was $50 \times 50 \mathrm{\mu m}^{2}$. The non-contact mode was used during the measurements. The root mean square (RMS) roughness of the surface was calculated using the AFM data analysis software Gwyddion [23]. An X-ray diffractometer (DRON 4-07) was used to determine the structural properties. All measurements were carried out using Ni-filtered $K_{\alpha}$ radiation of copper anode $(U=30 \mathrm{kV}$, $I=20 \mathrm{~mA}$ ) in a $2 \theta$ angle range from $20^{\circ}$ to $80^{\circ}$, where $2 \theta$ is the Bragg angle in the continuous registration mode (speed of $1^{\circ} / \mathrm{min}$ at 0.02 degree steps). The focusing Bragg-Brentano geometry was used in the studies. XRD patterns were normalized to the intensity of the (200) peak of the cubic $\mathrm{MgO}$ phase. Experimental results were transferred directly into the DifWin software (Etalon PTC, Ltd., Moscow, Russian Federation) for data analysis. The accuracy of determination of the lattice constant of the material was $0.001 \%$. The method of determining the basic structural characteristics of the films of $\mathrm{A}_{2} \mathrm{~B}_{6}$ compounds is described in detail in [24].

The optical properties of the films were examined in the wavelength range of $320-1000 \mathrm{~nm}$ by using a spectrophotometer (UV-Vis $721 \mathrm{G}$ ). The photoluminescence measurements were carried out at room temperature using a $\mathrm{He}-\mathrm{Cd}$ laser (wavelength $325 \mathrm{~nm}$ ) as the excitation source. A laser beam with a power of $\approx 4 \mathrm{~mW}$ was focused on a line of $\approx 5 \mathrm{~mm} \times 50 \mu$ using a cylindrical lens in a quasi-backscattering configuration. A JobinYvon TRIAX iHR-550 spectrometer (300 grooves/mm, blazed at $600 \mathrm{~nm}$ ) with a slit width of $0.1 \mathrm{~mm}$ was used to disperse the signal. The signal was detected with a liquid-nitrogen-cooled back-illuminated charge-coupleddevice (CCD) detector array.

\section{Results and discussion}

SEM images of the obtained thin films are shown in Fig. 1. It can be seen that the films have a polycrystalline structure and relatively high surface roughness. The inset of Fig. 1 shows the typical profile of the film surface obtained using the Dektak profiler. The film thickness of $\mathrm{MgO}$ was in the range of $d \approx 0.1 \mu \mathrm{m}$ as summarized in Table I.
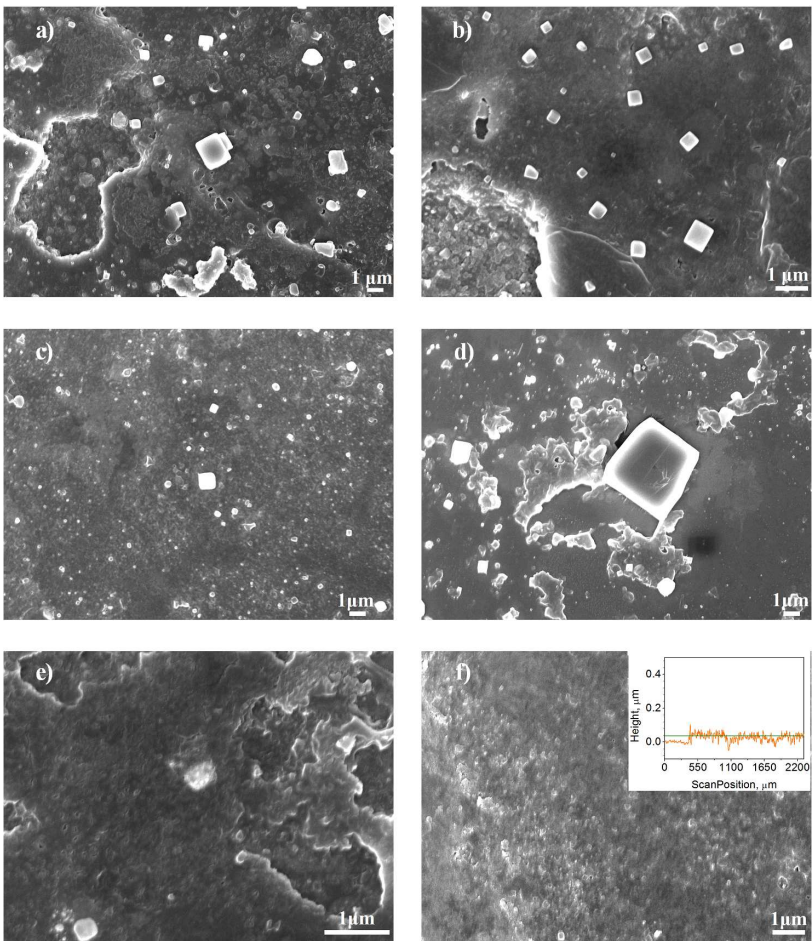

Fig. 1. FE-SEM images of samples obtained at $T_{\mathrm{S}}[\mathrm{K}]$ 643 (a), 653 (b), 663 (c), 673 (d), 683 (e), and 693 (f). (Inset) A typical profile of the film surface obtained using Dektak profiler.

TABLE I

Characteristics of $\mathrm{MgO}$ films.

\begin{tabular}{c|c|c|c|c|c|c|c|c}
\hline \hline $\begin{array}{c}T_{\mathrm{s}} \\
{[\mathrm{K}]}\end{array}$ & $\begin{array}{c}d \\
{[\mathrm{~nm}]}\end{array}$ & $\begin{array}{c}R_{\mathrm{a}} \\
{[\mathrm{nm}]}\end{array}$ & $\begin{array}{c}R_{\mathrm{q}} \\
{[\mathrm{nm}]}\end{array}$ & $\begin{array}{c}f \\
\text { [arb. u.] }\end{array}$ & $\begin{array}{c}a \\
{[\mathrm{~nm}]}\end{array}$ & $\begin{array}{c}L \\
{[\mathrm{~nm}]}\end{array}$ & $\begin{array}{c}\varepsilon \\
\times 10^{3}\end{array}$ & $\begin{array}{c}E_{g} \\
{[\mathrm{eV}]}\end{array}$ \\
\hline 643 & 119.5 & 26.2 & 33.7 & 2.6 & 0.42154 & 42.8 & 2.75 & 3.57 \\
653 & 109.3 & 18.4 & 23.1 & 2.4 & 0.42214 & 27,9 & 1.89 & 3.38 \\
663 & 109.7 & 13.2 & 16.7 & 3.0 & 0.42270 & 16.2 & 1.91 & 3.69 \\
673 & 105.3 & 15.1 & 19.1 & 2.8 & 0.42206 & 29.6 & 3.19 & 3.64 \\
683 & 97.6 & 23.5 & 29.9 & 2.9 & 0.42196 & 40.7 & 4.35 & 3.68 \\
693 & 85.3 & 12.2 & 15.6 & 3.6 & 0.42161 & 40.7 & 4.35 & 3.70
\end{tabular}

As follows from Fig. 1 the $\mathrm{MgO}$ films were nanostructured. With increasing substrate temperature, the crystallite size increased from $1 \mu \mathrm{m}$ at $643 \mathrm{~K}$ to $200 \mathrm{~nm}$ at $673 \mathrm{~K}$. In some cases, much larger crystals with a shape typical for substances with a cubic crystal lattice were detected. These data are confirmed by the AFM images of the film surface as shown in Fig. 2. It can be seen that the films have a homogeneous surface with tightly packed grains. The inset of Fig. 2 shows a typical profile of the film surface obtained by using AFM. The average surface roughness $R_{\mathrm{a}}$ and the root-mean-square roughness $R_{\mathrm{q}}$ were calculated for quantitative estimation of the surface roughness. The corresponding results are presented 
in Table I. The film roughness depends on the substrate temperature. It was found that increasing the substrate temperature from $T_{\mathrm{s}}=643 \mathrm{~K}$ to $T_{\mathrm{s}}=663 \mathrm{~K}$ leads to reduced surface roughness. With further increase of $T_{\mathrm{S}}$, both $R_{\mathrm{a}}$ and $R_{\mathrm{q}}$ increase.
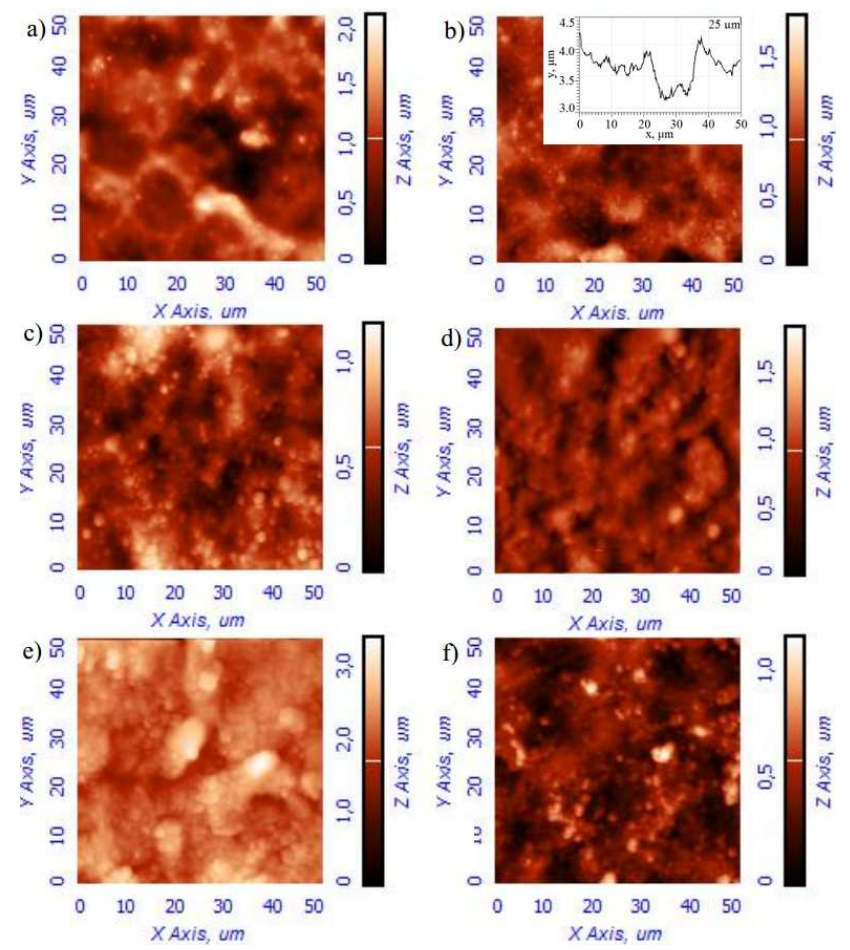

Fig. 2. AFM images of $\mathrm{MgO}$ thin films obtained at $T_{\mathrm{s}}[\mathrm{K}]: 643$ (a), 653 (b), 663 (c), 673 (d), 683 (e), and 693 (f). (Inset) A typical profile of the film surface obtained using AFM.

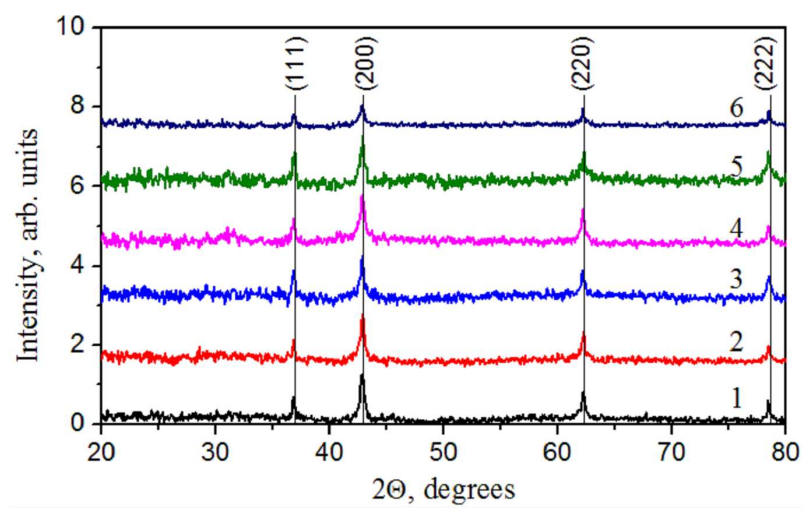

Fig. 3. X-ray diffraction patterns of $\mathrm{MgO}$ films deposited at substrate temperatures of $T_{\mathrm{s}}[\mathrm{K}]: 643(1)$, 653 (2), 663 (3), 673 (4), 683 (5), and 693 (6).

Figure 3 shows X-ray diffraction patterns of the $\mathrm{MgO}$ films deposited at different growth conditions. The $\mathrm{X}$ ray patterns show peaks at $2 \theta=36.80^{\circ}, 42.84^{\circ}, 62.16^{\circ}$, and $78.44^{\circ}$, which are identified as reflections from the (111), (200), (220), and (222) planes of the cubic $\mathrm{MgO}$ phase [25] (JCPDS 01-075-0477). Reflection from crystallographic planes of other phases is not observed, which indicates that the thin films are single phase. It should be noted that we detected hydroxyl compounds of magnesium, such as a $\mathrm{Mg}_{2}(\mathrm{OH})_{3} \cdot \mathrm{Cl}_{4} \cdot \mathrm{H}_{2} \mathrm{O}$, by X-ray diffraction in films obtained at substrate temperatures below $643 \mathrm{~K}[15]$.

$\mathrm{X}$-ray diffraction analysis showed that reflections from crystallographic (111) and (200) planes of the cubic phase of $\mathrm{MgO}$ are dominant, which indicates the presence of growth texture in the films. Further calculations of the pole density $P_{i}$ and the orientation factor $f$ (Table I) confirmed the presence of pronounced axial [111] growth texture of $\mathrm{MgO}$ layers. A similar growth texture was also observed in $[26,27]$. It was found that the texture of films slightly improved with increased substrate temperature.
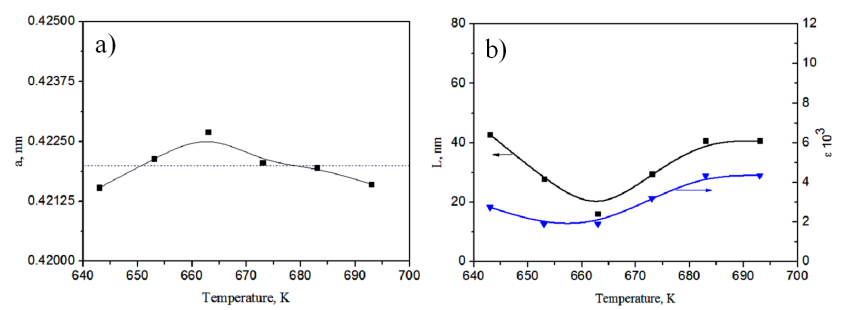

Fig. 4. Effect of substrate temperature on lattice constant $a$ reference data (dashed line) (a) and CSD size $L$ and level of microstrains $\varepsilon$ (b) of MgO films.

The lattice constants were determined using the Nelson-Riley extrapolation method. The lattice constant of the $\mathrm{MgO}$ layers varied in the range from 0.42154 to $0.42270 \mathrm{~nm}$. Their influence of substrate temperature on the lattice constant has a non-monotonic behavior (Fig. 4a). With the increase of the substrate temperature, we observed a gradual increase in the lattice constant, and then slight decrease. The values are all similar to the reference data $(a=0.42200 \mathrm{~nm}[25])$.

Estimations of the substructural parameters of the films were carried out for the [111] direction of the crystal lattice of the cubic phase (by reflections from the (100) and (222) planes) by threefold convolution [24]. The results for dimensions of CSD and microstrains are shown in Fig. 4b and Table I.

It is shown (Fig. 4b) that increasing the substrate temperature of thin films leads to decrease of CSD from $L \sim 43 \mathrm{~nm}\left(T_{\mathrm{s}}=643 \mathrm{~K}\right)$ to $L \sim 16 \mathrm{~nm}\left(T_{\mathrm{s}}=663 \mathrm{~K}\right)$ in the [111] direction and then increase to $L \sim 41 \mathrm{~nm}$ $\left(T_{\mathrm{s}}=693 \mathrm{~K}\right)$. Similar values of CSD sizes $(L=15 \mathrm{~nm})$ were obtained in [20] by using the Scherrer equation for magnesium oxide films deposited at temperatures of $673 \mathrm{~K}$ and $723 \mathrm{~K}$ from solutions of magnesium acetylacetonate as a precursor. Also, similar values of CSD of $16 \mathrm{~nm}$ were obtained in [11]. These authors synthesized films at a temperature range from $T_{\mathrm{s}}=673 \mathrm{~K}$ to $873 \mathrm{~K}$ using magnesium acetate as a precursor in ethanol with $\mathrm{HCl}$ and TEG. Slightly larger values of CSD were found in compounds of $\mathrm{A}_{2} \mathrm{~B}_{6}$ films deposited by close-spaced vacuum sublimation [28-31]. 
The dependence of microstrains on substrate temperature in the studied films (Fig. 4b) is similar to substrate temperature dependences of CSD. The microstrain of thin films decreases from $2.75 \times 10^{-3}\left(T_{\mathrm{s}}=643 \mathrm{~K}\right)$ to $1.89 \sim 10^{-3}\left(T_{\mathrm{s}}=653 \mathrm{~K}\right)$ and then increases to $4.35 \times 10^{-3}\left(T_{\mathrm{s}}=693 \mathrm{~K}\right)$.
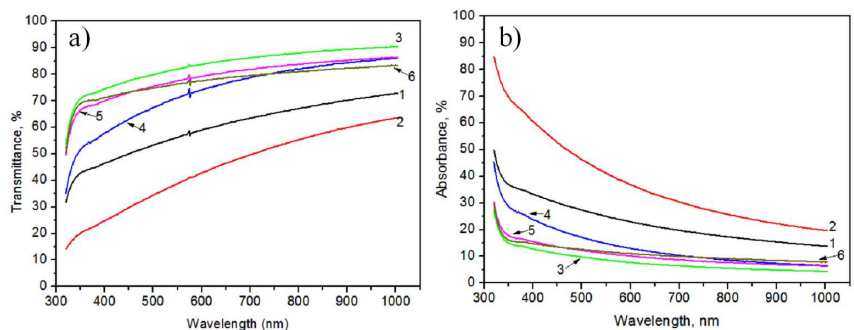

Fig. 5. Transmittance spectra (a) and absorbance spectra (b) of $\mathrm{MgO}$ thin films obtained at substrate temperature $T_{\mathrm{s}}[\mathrm{K}]: 643$ (1), 653 (2), 663 (3), 673 (4), 683 (5), and 693 (6).

Transmittance spectra of magnesium oxide films deposited on glass substrates are presented in Fig. 5a. The highest value of transmittance is obtained at substrate temperatures of $T_{\mathrm{s}}=663 \mathrm{~K}$ and $683 \mathrm{~K}$. The layers obtained at the lower temperatures show lowest values of transmittance $(643$ and $653 \mathrm{~K}$ ). This is a good correlation with the literature data $[2,8,20,22,32,33]$. The decrease in transmittance could be explained by the increased concentration of defects and the presence of additional grain boundaries.

The optical absorption coefficients $(\alpha)$ of these films were determined from the transmittance spectra using the Lambert equation

$$
\alpha=\ln (1 / T) / d,
$$

where $d$ is the film thickness and $T$ is the transmittance [34]. It should be noted that reflection from the layers is not taken into account.

Figure 5b shows calculated absorbance spectra of magnesium oxide films. As expected the highest absorption is observed in films obtained at lower substrate temperatures. For determination of the optical band gap energy $\left(E_{g}\right)$, we used the following equation, which is suitable for both direct and indirect band gap materials

$$
\alpha h \nu=A\left(h \nu-E_{g}\right)^{n},
$$

where $A$ is some constant that depends on the effective mass of charge carriers in the material, $h \nu$ is the energy of the photon, and $n$ is a number that depends on the nature of the transition. In this case this value was found to be $1 / 2$ (which corresponds to a direct band-to-band transition).

Figure 6 shows the typical dependence of $(\alpha h \nu)^{2}$ versus $h \nu$ for the obtained $\mathrm{MgO}$ films. The intersection of the straight line with the $h \nu$-axis gives the optical band gap energy $E_{g}[35]$. The corresponding results are present in Table I. The band gap energy of the films increases with substrate temperature in the range from 338 to $370 \mathrm{eV}$.
It should be noted that these values were significantly lower than the band gap of bulk $\mathrm{MgO}\left(E_{g}=73 \mathrm{eV}[2]\right)$. The observed optical band gap energy, therefore, corresponds not to the intrinsic band gap of $\mathrm{MgO}$ but to some below-band-gap optical transitions due to impurities, etc. The values $\left(E_{g}=3.81-3.92 \mathrm{eV}\right)$ similar to ours were presented in [32]. In this study the magnesium oxide thin films were obtained by spin-coating using a $0.1 \mathrm{M} \mathrm{Mg}$ ion solution that was prepared by dissolving magnesium nitrate hexahydrate $\left[\mathrm{Mg}\left(\mathrm{NO}_{3}\right)_{2} \cdot 6 \mathrm{H}_{2} \mathrm{O}\right]$ in ethanol $\left[\mathrm{C}_{2} \mathrm{H}_{5} \mathrm{OH}\right]$. Nitric acid was then added to the solutions as a stabilizer. A much lower band gap energy value of $E_{g}=2.5 \mathrm{eV}$ was reported in [22] for thin films obtained by spray pyrolysis. They used $0.05 \mathrm{M}$ of magnesium chloride hexahydrate dissolved in deionized water as a precursor solution. A higher value of $E_{g}=4.51 \mathrm{eV}$ was found for $\mathrm{MgO}$ nanowires synthesized by solvothermal method [36]. The values of the band gap in the range from 4.1 to $4.6 \mathrm{eV}$ were found for nanoparticles obtained by chemical precipitation [37] and $E_{g}=4.2 \mathrm{eV}$ for nanoparticles deposited by spray pyrolysis [38]. Larger band gap values found in these studies were attributed to the small size of nanoparticles.

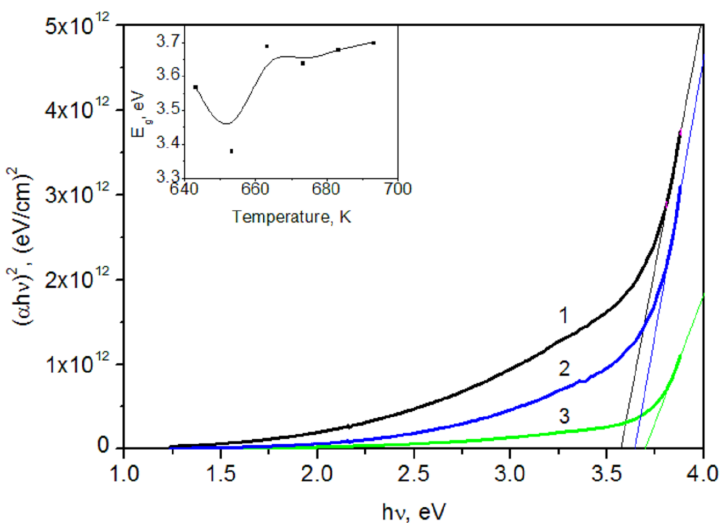

Fig. 6. Typical dependence $(\alpha h \nu)^{2}$ vs. $h \nu$ of $\mathrm{MgO}$ thin films obtained at $T_{\mathrm{s}}[\mathrm{K}]: 643(1), 673(2)$, and $663(3)$. Inset: dependence bandgap energy $E_{g}$ vs. temperature $T$ of $\mathrm{MgO}$ thin film.

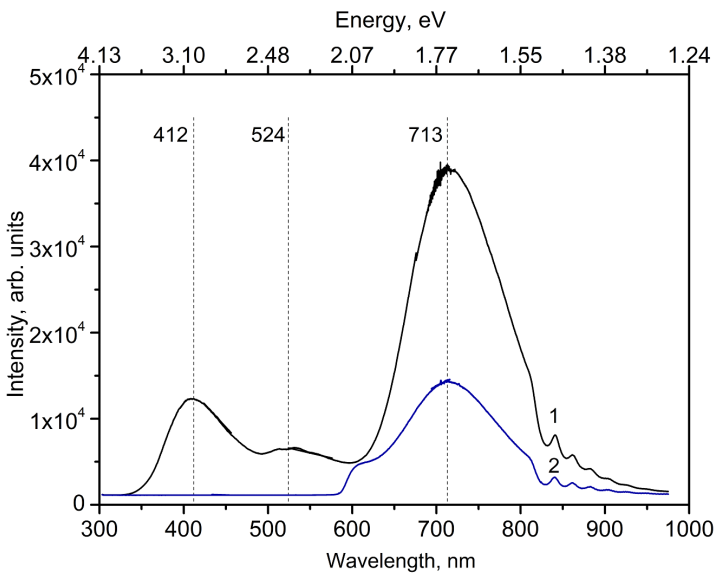

Fig. 7. Typical photoluminescence spectra of (1) $\mathrm{MgO}$ and (2) glass substrate. 
The room-temperature photoluminescence (PL) spectra of magnesium oxide films are presented in Fig. 7. The PL spectra show emission peaks at approximately $412 \mathrm{~nm}(3.00 \mathrm{eV})$ and $524 \mathrm{~nm}(2.38 \mathrm{eV})$. The peak at $3.00 \mathrm{eV}$ could be assigned to holes trapped on magnesium ion vacancies acting as acceptors $\left(\mathrm{F}^{+}\right.$center). The broad emission peak at $524 \mathrm{~nm}$ is related to the presence of defects $\left(\mathrm{F}^{-}\right.$centers) associated with oxygen ion vacancies. These results are in good correlation with previous work [39-41]. In order to exclude the influence of the substrate, we also measured the PL spectrum of the glass substrate. As can be seen from Fig. 7, the peak at $713 \mathrm{~nm}$ on the $\mathrm{MgO}$ spectrum corresponds to a $\mathrm{PL}$ signal from the glass substrate, although its intensity is a bit higher.

\section{Conclusion}

Nanostructured magnesium oxide films have been obtained by a simple and effective spray pyrolysis method in the substrate temperature range of $T_{\mathrm{s}}=643 \mathrm{~K}$ to $693 \mathrm{~K}$. The magnesium chloride hexahydrate $\left(\mathrm{MgCl}_{2} \cdot 6 \mathrm{H}_{2} \mathrm{O}\right)$ aqueous solution was used as a precursor solution. It was established that $\mathrm{MgO}$ thin films have a single-phase, a cubic structure with a [111] growth texture. The lattice constant of the $\mathrm{MgO}$ layer varied in the range of $a=0.42154 \mathrm{~nm}$ to $0.42270 \mathrm{~nm}$ and slightly increased at the substrate temperatures of $T_{\mathrm{s}}=643-663 \mathrm{~K}$. The CSD sizes in the $\mathrm{MgO}$ films and the microstrain in directions perpendicular to the crystallographic (111) planes were $L_{(111)}=16.2-42.8 \mathrm{~nm}$ and $\varepsilon \approx(1.89-4.35) \times 10^{-3}$, respectively. The films obtained at substrate temperatures higher than $663 \mathrm{~K}$ have quite a good transmittance $(80-90 \%)$ in a wide wavelength range. The optical band gap values were found to be $E_{g}=3.64-3.70 \mathrm{eV}$, which is much lower than the band gap of bulk material. The observed optical band gap of the films increased with the substrate temperature. The PL spectra show emission peaks at $\approx 412 \mathrm{~nm}(3.00 \mathrm{eV})$ and at $\approx 524 \mathrm{~nm}$ $(2.38 \mathrm{eV})$, which were attributed to positively and negatively charged $\mathrm{F}^{-}$centers. The $\mathrm{MgO}$ layers, obtained by spray pyrolysis in this work can be used as a window or a protective layer in solar cells and other optoelectronic devices, thanks to their high optical properties.

\section{Acknowledgments}

This work was supported by the State Fund for Fundamental Research (project No. F61/70-2015), by the Ministry of Education and Science of Ukraine (Grant No. 0113U000131, 0115U000665c), and by the New \& Renewable Energy of the Korea Institute of Energy Technology Evaluation and Planning (KETEP) grant funded by the Korea government Ministry of Trade, Industry and Energy (No. 20123010010130).

\section{References}

[1] B.O. Satishchandra, Thin Films and Heterostructures for Oxide Electronics, Springer Science \& Business Media, New York 2006.
[2] M.M. Habeeb, M.H. Jaddaa, A.H.K. Elttayef, H.M. Ajeel, Int. J. Appl. Innovat. Eng. Manag. 3, 94 (2014).

[3] I.C. Ho, Y. Xu, J.D. Mackenzie, J. Sol-Gel Sci. Technol. 9, 295 (1997).

[4] G. Bergeret, in: Handbook of Heterogeneous Catalysis, Eds. G. Ertl, H. Knozinger, J. Weitkamp, Vol. 2, Wiley-VCH, Weinheim 1997.

[5] Y.W. Choi, J. Kim, Thin Solid Films 460, 295 (2004).

[6] T. Naoi, H. Lin, A. Hirota, E. Otani, K. Amemiya, J. Soc. Inform. Display 17, 2 (2009).

[7] S. Yuasa, D.D. Djayaprawira, J. Phys. D Appl. Phys. 40, R337 (2007).

[8] M.A. Farag, M. El-Okr, R.M. Mahani, G.M. Turky, H.H. Afify, Int. J. Adv. Eng. Technol. Comput. Sci. 1, 1 (2014).

[9] G. Grinblat, F. Bern, J. Barzola-Quiquia, M. Tirado, D. Comedi, P. Esquinazi, Appl. Phys. Lett. 104, 103113 (2014).

[10] F. Niu, B.H. Hoerman, B.W. Wessels, MRS Proc. 619, 149 (2000).

[11] J.M. Zeng, H. Wang, S.X. Shang, Z. Wang, M. Wang, J. Cryst. Growth 169, 474 (1996).

[12] S. Kaneko, T. Ito, M. Soga, Y. Motoizumi, M. Yasui, Y.Y. Hirabayashi, Jpn. J. Appl. Phys. 52, 01AN02 (2013).

[13] J.H. Boo, S.B. Lee, K.S. Yu, W. Koh, Y. Kim, Thin Solid Films 341, 63 (1999).

[14] J.G. Yoon, H.K. Kim, J. Korean Phys. Soc. 31, 613 (1997).

[15] A.V. Dyachenko, A.S. Opanasuyk, D.I. Kurbatov, S.B. Bolshanina, V.M. Kuznetsov, Proc. Int. Conf. on Nanomaterials: Applications and Properties, Sumy State University Publishing, Sumy, Vol. 3 , 2014, p. 01PCSI05.

[16] F. Niu, B.H. Hoerman, B.W. Wessels, MRS Proc. 619, 149 (2011).

[17] O.V. Diachenko, A.S. Opanasuyk, D.I. Kurbatov, V.M. Kuznetsov, H. Cheong, Funct. Mater. 22, 487 (2015).

[18] J.P. Singh, C.L. Chen, C.L. Dong, J. Prakash, D. Kabiraj, D. Kanjilal, K. Asokan, Superlatt. Microstruct. 77, 313 (2015).

[19] J.P. Singh, I. Sulania, J. Prakash, S. Gautam, K.H. Chae, D. Kanjilal, K. Asokan, Adv. Mater. Lett. 3, 112 (2012).

[20] A.M.E. Raj, V.B. Jothy, C. Ravidhas, T. Som, M. Jayachandran, C. Sanjeeviraja, Radiat. Phys. Chem. 78, 914 (2009).

[21] X. Yi, W. Wenzhong, Q. Yitai, Y. Li, C. Zhiwen, Surf. Coat. Technol. 82, 291 (1996).

[22] S. Nisatharaju, R. Ayyappa, D. Balamurugan, Asian J. Appl. Sci. 7, 780 (2014).

[23] D. Nečas, P. Klapetek, Open Phys. 10, 1322 (2012).

[24] X-ray Diffraction, Ed. B.E. Warren, Dover, New York 1990.

[25] Selected powder diffraction data for education straining, Search Manual and Data Cards, International Centre for Diffraction Data, USA 1997. 
[26] O. Yeheskel, R. Chaim, Z. Shen, M. Nygren, J. Mater. Res. 20, 719 (2005).

[27] S.G. Kim, J.Y. Kim, H.J. Kim, Thin Solid Films 376, 110 (2000).

[28] A.D. Pogrebnjak, A.P. Shypylenko, H. Amekura, Y. Takeda, A.S. Opanasyuk, D.I. Kurbatov, I.A. Kolotova, O.V. Klymov, C. Kozak, Acta Phys. Pol. A 123, 939 (2013).

[29] D. Kurbatov, V. Kosyak, M. Kolesnyk, A. Opanasyuk, S. Danilchenko, Integrat. Ferroelectr. 103, 32 (2008).

[30] C.J. Panchal, A.S. Opanasyuk, V.V. Kosyak, M.S. Desai, I.Y. Protsenko, J. Nano-Electron. Phys. 3, 274 (2011).

[31] A.S. Opanasyuk, D.I. Kurbatov, V.V. Kosyak, S.I. Kshniakina, S.N. Danilchenko, Crystallogr. Rep. 57, 927 (2012)

[32] S. Valanarasu, V. Dhanasekaran, M. Karunakaran, T.A. Vijayan, R. Chandramohan, T. Mahalingam, J. Mater. Sci. Mater. Electron. 25, 3846 (2014).

[33] X. Fu, G. Wu, S. Song, Z. Song, X. Duo, C. Lin, Appl. Surf. Sci. 148, 223 (1999).
[34] J.W. Chen, D.C. Perng, J.F. Fang, Solar En. Mater. Solar Cells 95, 2471 (2011).

[35] H. Kidowaki, T. Oku, T. Akiyama, A. Suzuki, B. Jeyadevan, J. Cuya, J. Mater. Sci. Res. 1, 138 (2012).

[36] N.M.A. Hadia, H.A.H. Mohamed, Mater. Sci. Semicond. Process. 29, 238 (2015).

[37] P.B. Devaraja, D.N. Avadhani, S.C. Prashantha, H. Nagabhushana, S.C. Sharma, B.M. Nagabhushana, H.P. Nagaswarupa, Spectrochim. Acta Part A: Mol. Biomol. Spectrosc. 118, 847 (2014).

[38] K.R. Nemade, S.A. Waghuley, Int. J. Met. 2014, 1 (2014).

[39] P. Edel, J. Phys. C Solid State Phys. 15, 1596 (1982).

[40] M. Li, X. Wang, H. Li, H. Di, X. Wu, C. Fang, B. Yang, Appl. Surf. Sci. 274, 188 (2013).

[41] C. Martinez-Boubeta, A. Martínez, S. Hernández, P. Pellegrino, A. Antony, J. Bertomeu, B. Martínez, Solid State Commun. 151, 751 (2011). 